\title{
Pediatric Neurologic Oncology
}

National Cancer Institute

\section{Source}

National Cancer Institute. Pediatric Neurologic Oncology. NCI Thesaurus. Code C17858.

A branch of neurologic oncology that focuses on cancers in children. 